\title{
Bacterial Sialidase Measurement
}

National Cancer Institute

\section{Source}

National Cancer Institute. Bacterial Sialidase Measurement. NCI Thesaurus. Code C154820.

The determination of the bacterial sialidase present in a sample. 